\title{
Gulf War syndrome revisited
}

\author{
The mysteries of Gulf War syndrome are being unravelled, but will it plaguethe soldiers now returning \\ from Iraq?
}

A stroops returned home from the war in Iraq in late A pril, many wondered whether some would soon fall ill, as did thousands of those who fought in the first Gulf War (GWI) in 1991. During the past 12 years, nearly half of the 700,000 GWI veterans have sought treatment for a wide range of symptoms that many suspect were linked to exposure to depleted uranium, pesticides, vaccines, particulate matter and gases from burning oil wells, biological and chemical weapons, and the antinerve-gas drug pyridostigmine bromide (PB). About $29 \%$ of soldiers who were deployed are now considered to be disabled due to their wartime service, $23 \%$ are receiving disability benefits, and tens of thousands of the rest are still plagued by illness, but do not fall into these categories because of the lack of a clear-cut diagnosis.

For more than a decade, soldiers were told that no single cause, except stress, could explain complaints as diverse as headaches, dizziness, fatigue, bone and joint pain, memory loss, problems with sleep and concentration, muscle weakness, skin rashes and sores, and gastrointestinal problems. The US government cited statistics that show ed that G W I veterans were not dying or being hospitalized at higher rates than other soldiers. However, it could not explain how stress could wreak such havoc on health, or why GWI veterans were being diagnosed with amyotrophic lateral sclerosis (ALS) at twice the rate of other groups. But new research is putting the stress diagnosis to rest and, after 12 years of desperation for the veterans, answers to the mystery surrounding GW syndrome are being found. This should lead not only to effective treatments, but also to more protection for soldiers and the general population against future military and terrorist attacks.

In June 2002, the 12-member Research Advisory Committee (RAC) on Gulf War Veterans' IIInesses released an interim report that brought together studies pointing to several types of neurological damage in the afflicted veterans (www.va.gov/RAC-GWVI). In the following O ctober, the U S government's

\section{"The [US] government is finally realizing that the nature of war is changing, and that soldiers can be damaged by weapons other than bullets and bombs"}

Department of Veterans Affairs (DVA) made a 180-degree turnaround by publicly acknowledging that strong evidence exists that many $\mathrm{GW}$ I veterans are suffering from brain damage caused by different combinations of exposure to toxins. Deputy Secretary Leo Mackay Jr admitted in an address to the RAC that, in the past, the US government had "a tin ear, cold heart and a closed mind" about toxic chemical exposure and drug-chemical interactions as possible causes of GW syndrome. "The [US] government is finally realizing that the nature of war is changing, and that soldiers can be damaged by weapons other than bullets and bombs," said Steve Robinson, Executive Director of the National Gulf W ar Resource Center (N G W RC; Silver Spring, M D, USA; www.ngwrc.org), a veterans' health advocacy group that was founded in 1995. According to this organization, incidences of illness in forward-deployed GW I units are higher than those in non-deployed units; $42 \%$ of those who entered Iraq and Kuwait are ill, as compared with $31 \%$ who served on land in support areas, and $21 \%$ who served on ships. Length of service, as well as location, is also significant, with longer tours correlating to more symptoms.

A long with earlier studies, evidence from research funded by the US Department of D efense (DoD) and published in the British Medical Journal (K. Ismail et al., 325, 576; 2002), was, said Mackay, undeniable. The study was conducted at three London hospitals and followed 12,000 disabled British veterans from the Bosnian and Gulf wars. The authors had previously hypothesized that a psychological condition, similar to stress, was the cause of GW syndrome, but the new study found that "posttraumatic stress disorder is not higher in Gulf veterans than in other veterans." Under the weight of this evidence, the DVA pledged to double the budget for research into the illness to an annual US $\$ 20$ million. Another reason for the US government's about-turn is the recognition that the biological and chemical agents that the soldiers encountered in the desert in 1991 are the ones that terrorists are threatening to use against the general population, suggested Robinson.

\section{...the biological and chemical agents that the soldiers encountered in thedesert in 1991 are the ones that terrorists are threatening to use against the general population...}

The O ffice of the Special Assistant for Gulf War IIInesses (OSAG W I) was formed in 1997, but "it spent almost $\$ 250$ million until 2002 without publishing any medical research report or offering a single treatment program for ill GW veterans," Robinson observed. Indeed, in 1997, the General Accounting Office (GAO), the investigatory arm of US Congress, reported that some researchers thought that they would not receive funding for research into the syndrome because of the DoD's position, and that it would be useless to try. Of the research that has been performed, much of the groundbreaking work was started about eight years ago by Robert Haley of Southwestern Texas Medical School (D allas, TX, USA), formerly at the Centers for Disease Control (Atlanta, GA, USA). Initially, Haley was funded by the Texan millionaire Ross Perot. Using magnetic resonance spectroscopy, Haley and others showed evidence of neuronal loss in the basal ganglia and brainstems of ill soldiers, and this research is summarized in the RAC Interim Report. "Veterans with cognitive problems show neuronal loss in the basal 


\section{science $\&$ society}

ganglia; those with muscle and joint problems show loss in the brain stem," it states.

\section{...all three [GW ] syndromes were strongly associated with exposure to acetylcholinesterase (AChE)-inhibiting organophosphates or carbamates}

In 1997, Haley reported that there are three primary syndromes in GW I veterans: syndrome 1 (impaired cognition) includes distractibility, forgetfulness, depression and daytime somnolence; syndrome 2 (confusion-ataxia) is characterized by more profound reduced intellectual processing, confusion, frequent disorientation and episodes of vertigo; syndrome 3 (central pain) is characterized by chronic somatic pain and parethesias of the extremities. Notably, Haley reported that all three syndromes were strongly associated with exposure to acetylcholinesterase (AchE)inhibiting organophosphates or carbamates. Syndrome 1 correlates to organophosphate pesticides in flea collars; syndrome 2 correlates to apparent lowlevel nerve agent exposure and advanced side-effects of PB; and syndrome 3 is also associated with exposure to $\mathrm{PB}$ and high concentrations of DEET insect repellant. Hans Kang, of the Central Veterans Affairs Office, surveyed 20,000 samples from deployed and non-deployed veterans from the GWI era and found three syndromes closely resembling those identified by Haley. He concluded that syndrome 2 was found only in the deployed GWI population and that these patients were most likely to be unemployed due to their symptoms. Research at the Hebrew U niversity (Jerusalem, Israel) led by Hermona Soreq, $\mathrm{PhD}$, has shown that AChE-inhibitors induce the long-term production of a variant form of an enzyme that is associated with animals that have electrophysiological hyperactivity, impaired working memory, hypersensitivity to head injury and weakened muscles. Earlier work by her group showed that PB crosses the blood-brain barrier more easily in stressed animals.

Other key findings from the affected veterans include an increased cold sensory threshold, abnormal audiovestibular tests that reflect subtle damage to brainstem reflex pathways and abnormal autonomic nervous system function, which is shown by an atypical heart rate during sleep. This could also explain the common complaints of poor sleep, morning fatigue, chronic pathogen-free diarrhoea and an increase in cholecystitis. Soldiers with syndrome 2, who had more brain cell damage in the left basal ganglia, had higher levels of brain dopamine production, a finding that is compatible with the upregulation of dopamine receptors after damage to dopaminergic pathways in basal ganglia.

$\mathrm{H}$ aley and others also found a genetic component to GW syndrome. Compared with a control sample, 26 affected veterans had much lower levels of the enzymes paraoxonase (PON1) and butyrylcholinesterase (BChE), which are responsible for inactivating organophosphates, and the levels were particularly low in those with syndrome 2 . M utation of the PON 1 gene is also associated with the development of Parkinson's disease (I. Kondo \& M. Yamamoto, Brain Research, 806, 271-273; 1998). Interestingly, sheep-dippers in the UK that had fatigue-cognitivepain syndromes that are similar to $G W$ syndrome and chronic fatigue syndrome, had the same gene variant ( $N$. Cherry et al., Lancet, 359, 763-764; 2002). Japanese researchers have cited the same PON 1 genotype in Asians as a possible explanation for the high impact of the low-level sarin exposures in the 1995 terrorist attack on the Tokyo subway. All these risk factors-exposures to environmental toxins, genetics, low-level nerve agents, depleted uranium, stress, medical countermeasures to bio- and chemical weapons, and combinations thereofare also relevant to domestic terrorism preparedness, the report notes.

A $\mathrm{s}$ in the Vietnam War, GWI was marked by poor record-keeping of toxic exposures, and much of what was available mysteriously disappeared, said Robinson. Veterans who became ill after contact with Agent Orange in Vietnam struggled for years to get the US government to acknowledge that contact had occurred and had a corresponding direct and negative effect on their health. A recent study stated that two million more gallons of Agent Orange and other defoliants had been sprayed over Vietnam than earlier estimates suggested (J.M. Stellman et al., N ature, 422, 681-687; 2003). GWI veterans face similar systematic cover-ups of exposures to chemical weapons and other toxins, according to congressman Chris Shays and others. In addition to records being destroyed, soldiers who were given vaccinations and prophylactic PB were not always told what they were taking. The US government's position was that toxic exposures could not be verified because sensors in the field were "unreliable." O ne source said that when marines crossed Iraqi minefields to reach Kuwait during GWI, they were exposed to poisonous gas. But with no accurate records, it was impossible to say that GWI veterans were ill because of the war-time exposures, the government said.

\section{Only time will tell whether veterans of the second Gulf War will suffer the same illnesses as those from the first}

In 1997, the government finally admitted that soldiers were exposed to poisonous gas when they bombed the Khamisiyah chemical depot during GWI. The estimated numbers of those exposed started at 100 , then rose to 10,000 , then 15,000 , and finally reached 100,000 . Last year, before Michael Kilpatrick was moved from leading the OSAGWI to run the public relations campaign for the second $\mathrm{GW}$, he said that any modelling to determine the exposure and dose rates of poisonous gas at Khamisiyah or elsewhere was "a wild-ass guess"-and indicated that the real number could be much higher than 100,000 . Veterans who served at Khamisiyah and Al Jubayl (another chemical depot that was destroyed) are 37\% more likely to have one or more serviceconnected conditions than other veterans, according to the NGW RC.

Despite efforts to cover up the facts, the NGWRC maintains that more than $250,000 \mathrm{GW}$ I veterans received the drug $\mathrm{PB}$, which was under investigation at the time, and which the Pentagon now admits it cannot rule out as a possible cause of GW syndrome. Eight thousand servicemen received the botulinum toxoid vaccine, 150,000 received the nowcontroversial anthrax vaccine, and 436,000 either entered or lived for months in areas contaminated by more than 315 tons of toxic waste, possibly containing 
trace amounts of highly radioactive plutonium and neptunium, without awareness, protective gear or medical evaluations. Hundreds of thousands lived outdoors near 700 burning oil-well fires for months without protection.

Whether soldiers during the recent war in Iraq were subject to the same or similar toxic exposures is an open question. O nly time will tell whether veterans of the second G ulf War will suffer the same illnesses as those from the first. "If they do, the cause this time will not be a mystery," Robinson said. "Now, the only mystery connected to Gulf War syndrome is whether the Department of Defense will do what Congress told them to do." Here, he is referring to a 1998 US law that requires that soldiers receive comprehensive physical examinations, including blood tests, before and after deployment. Before the war began in M arch, the DoD declared that it had learned from its mistakes; the troops were being equipped with better environmental sensors and other testing apparatus, and better gas masks and suits. It also said that it would assess soldiers' health using brief questionnaires, before and after deployment. However, the protective equipment was substandard and, according to civilian health experts who testified in Congress on March 25, 2003, once-yearly blood tests for HIV do not fulfil the requirements for comprehensive examinations, which should include lab tests and X-rays immediately before and after deployment. Two days later, at the House Armed Services subcommittee, lawmakers noted that many soldiers did not even fill out the questionnaires, and Robinson said that those that did were likely to give answers that would allow them to be deployed and remain with their units. Twelve years after GWI, it seems that the military is making some of the same mistakes again. However, the DoD stated on April 29, 2003 , that it would provide a more comprehensive, face-to-face examination for the returning soldiers. Calling it a "first step", Robinson and the NGWRC are still insisting that baseline data should have been collected. Soldiers who are fighting terrorism around the world should not experience the same system failures that $\mathrm{GWI}$ veterans continue to face, he added.

\section{Vicki Brower}

doi:10.1038/s..embor.embor874

\section{Local solutionsfor global problems}

\author{
With the gap between the rich and the poor becoming wider, \\ participants of thethird bioVision meeting discussed how the life \\ sciences can help
}

A t the beginning of the twenty-first century, the world seems more divided than ever: the rich are becoming richer and the poor are becoming poorer. The global consequences of this stark contrast between the 'haves' and the 'have-nots', and between the developed and the developing world, was one of the main topics of the third bioVision meeting held in Lyon, France, during 8-11 April 2003. Around 2,000 representatives from science, society and industry gathered to discuss the current state of the world and to what degree biotechnology could contribute to solving the numerous problems that plague humanity.

The huge gap between the developed and the developing world is best characterized by the availability of food. Although there is plenty of food available to feed the world's population-with or without genetically modified (GM) crops-its equal distribution remains a monumental challenge. Malnutrition still affects 800 million people in developing countries and it is an important contributing factor to half of the deaths of millions of children each year from infectious diseases. Access to adequate and safe food-and, equally importantly, clean drinking water-was regarded as a basic human right by the speakers and attendees of the conference. However, as Mary Robinson, former United Nations (UN) High Commissioner for Human Rights, and Head of the Ethical Globalization Initiative in New York, pointed out, this should not equate to the free distribution of surplus food from wealthier to poorer countries, but rather to the implementation of programmes aimed at establishing sustainable development throughout the world. Robinson also suggested that any progress in these areas should be monitored by independent organizations, such as the UN. Indeed, as M.S. Swaminathan, President of the Pugwash Conferences on Science and World Affairs, commented, any state that has signed and ratified a constitutionally guaranteed right to food for its population is then under great pressure to provide what was promised. He cited occasions in India when such a constitutional guarantee caused communities to seek and acquire aid from the Indian government.

Jacques Diouf, Director General of the UN Food and Agriculture Organization, suggested some concrete initiatives to favour economic growth in the rural communities of developing countries. Sustainable agriculture and rural development are essential for the implementation of an integrated approach to increasing food production and for enhancing food security and food safety, he explained. Therefore, local producers and farmers would be better assisted by guaranteed purchasing of their products rather than through financial aid. Such a guarantee would also be effective in transferring new agricultural technologies and

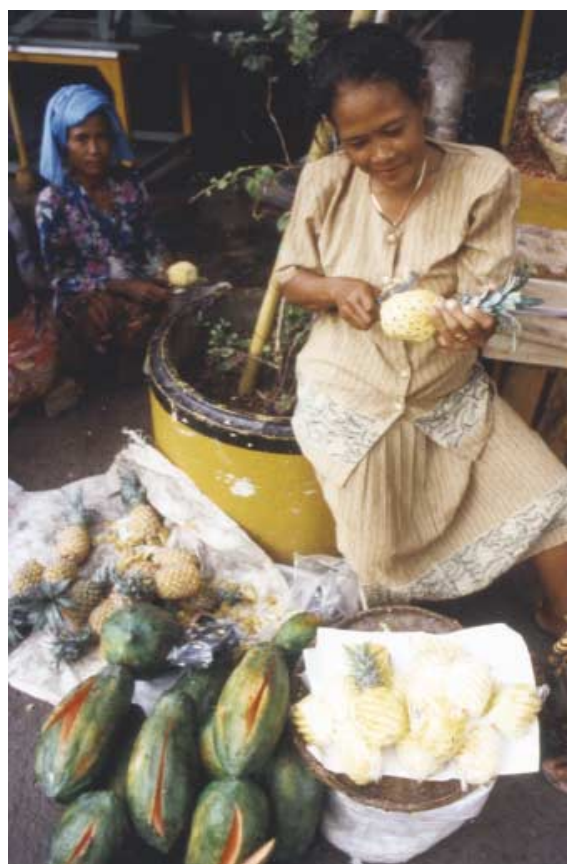

